\title{
Widespread occurrence of polypeptides related to neurotubule- associated proteins (MAP-1 and MAP-2) in non-neuronal cells and tissues
}

\author{
Gerhard Wiche*, Esthér Briones, Christiane Koszka, \\ Ulrike Artlieb $^{1}$ and Reinhard Krepler ${ }^{1}$
}

\author{
Institute of Biochemistry, University of Vienna, Währinger Strasse 17, 1090 \\ Vienna, and 'Department of Pathology, Division of Molecular Pathology \\ (Hans Popper-Laboratory), School of Medicine, University of Vienna, \\ 1090 Vienna, Austria \\ *To whom reprint requests should be sent \\ Communicated by J.V. Small
}

The occurrence and cellular localization of polypeptides related to hog brain microtubule-associated proteins 1 and 2 (MAP-1 and MAP-2) in non-neuronal cell lines of various species and types, and in several tissues from rat was studied. When insoluble cell fractions were prepared by incubation of isotonic cell extracts with $20 \mu M$ taxol, polypeptides comigrating with MAP-1 and MAP-2 upon gel electrophoresis were observed in virtually all cases examined. Immunoblotting of preparations from 3T6, CHO, HeLa and $\mathrm{N}_{2} \mathrm{~A}$ cells, as well as pituitary, heart, testis and liver revealed immunoreactivity with antibodies to neuronal MAP-1 for polypeptides co-migrating with MAP-1 in all cases, except for HeLa cells and liver. With similar preparations, antibodies raised to neuronal MAP-2 were barely reactive with bands of the MAP-2 size except for $\mathbf{N}_{2} A$ cells and pituitary gland. In all cases of non-neuronal cells and tissues, major cross-reactive bands, however, were of mol. wt. lower than that of MAP-2, indicating, most likely, proteolytic breakdown of MAP-2 during cell fractionation. As shown by double immunofluorescence microscopy of various cultured cell lines using affinity-purified antibodies to MAPs, and monoclonal antibodies to tubulin, MAP-1- as well as MAP-2-related antigens were generally, but not exclusively, associated with typical microtubule structures of the cytoplasm, spindle, midbody and primary cilia. Antigens related to both MAPs were also localized in frozen sections of rat trachea, testis, pituitary, kidney and cardiac and skeletal muscle. It is concluded that MAP-1- as well as MAP-2-related polypeptides occur in a wide variety of non-neuronal cells and tissues and apparently are tissue specific.

Key words: MAP-1 and -2/microtubules/non-neuronal cells/ rat tissues

\section{Introduction}

Microtubule-associated proteins 1 and 2 (MAP-1 and MAP-2) are high mol. wt. polypeptides from mammalian brain, which both stimulate the in vitro polymerization of microtubules (Murphy and Borisy, 1975; Sloboda et al., 1976; Herzog and Weber, 1978; Kuznetsov et al., 1981; Vallee and Davis, 1983) and form protrusions of considerable length on the surface of the polymer (Murphy and Borisy, 1975; Dentler et al., 1975; Amos, 1977). These proteins therefore, probably play key roles not only in the assembly and disassembly of microtubules but also in the mediation of their interaction with other cell organelles. As recently shown,
MAP-1 and MAP-2 from porcine brain are distinct proteins, though with partially homologous structure (Herrmann et al., 1984 ), that are differentially distributed in neuronal tissues (Wiche et al., 1983a).

Because of the potential importance of MAP-1 and MAP-2 for microtubular functions in general, related proteins have been searched for in non-neuronal cell types, but so far no coherent picture has emerged. In early immunofluorescence microscopy studies the occurrence of such proteins in a few selected cell lines was shown without discriminating between MAP-1 and MAP-2 (Sherline and Schiavone, 1977; Conolly et al., 1978; Sheterline, 1978). Studies carried out with defined antibodies to MAP-2 (Peloquin and Borisy, 1979) including a monoclonal antibody (Izant and McIntosh, 1980), failed to confirm these data, except for recent reports where antigens related to MAP-2 were identified in bovine tracheal epithelium cells (Kuznetsov et al., 1980), nucleated erythrocytes (Sloboda and Dickersin, 1980), HeLa cells (Weatherbee et al., 1982) and pig kidney cells (Valdivia et al., 1982). Furthermore, in a number of studies (Doenges et al., 1977; Nagle et al., 1977; Weatherbee et al., 1978; Bulinsky and Borisy, 1979) with various cultured cell lines, polypeptides resembling high mol. wt. MAPs in their mol. wt. did not co-purify with microtubules through repeated cycles of spontaneous in vitro polymerization, although such proteins were observed in rat glioma C6 (Wiche and Cole, 1976) and PC12 (Greene et al., 1983) cells, and were found to co-cycle with exogenous microtubule proteins in the case of SV 101 cells (Klein et al., 1978; Cleveland et al., 1979).

Using immunoblotting and immunofluorescence microscopy techniques we show here that MAP-1- as well as MAP2-related polypeptides occur in a wide variety of nonneuronal cell types, and furthermore, that both protein species are ubiquitously, though not exclusively, associated with microtubule structures. Moreover, the data presented allow preliminary conclusions to be drawn regarding the tissue specificity of these protein species.

\section{Results}

Identification of antigens related to MAP-1 and -2 in nonneuronal cultured cells and tissues

In crude extracts of non-neuronal cell cultures and tissues the relative amount of polypeptides co-migrating with hog brain MAP-1 or MAP-2 upon SDS-polyacrylamide gel electrophoresis generally was very low. Such polypeptides, however, were found to be enriched in preparations of microtubules polymerized from cell and tissue extracts using taxol under isotonic conditions (Koszka et al., in preparation) (Figure 1). A survey of nine non-neuronal cell lines including fibroblasts and epithelia-derived cells of various species revealed the general occurrence of two closely spaced double bands at the position of MAP-2 and a single or double band at the position of MAP-1. The estimated proportion of high mol. wt. polypeptides to tubulin varied considerably among different 


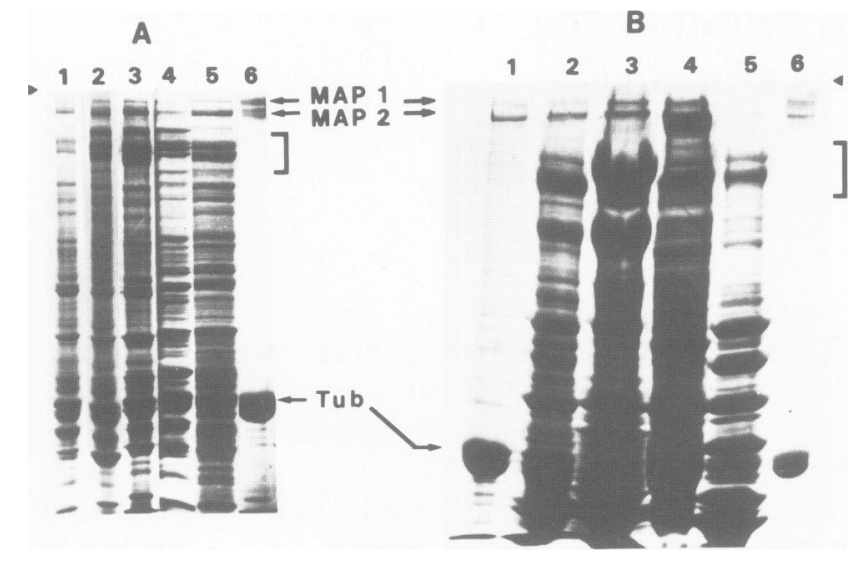

Fig. 1. Electrophoresis of taxol-precipitates from various cultured cell lines and rat tissues. Microtubule-enriched fractions (see text) were analyzed on $7.5 \%$ polyacrylamide gels. Coomassie Blue-stained gel bands are shown. A, cultured cell lines. Lanes: 1, $\mathrm{N}_{2} \mathrm{~A} ; 2, \mathrm{CHO} ; 3,3 \mathrm{T6}$; 4, HeLa; 5, C6; 6, hog brain microtubule proteins. B, Rat tissues. Lanes: 1, pituitary gland; $\mathbf{2}$, heart; $\mathbf{3}$, liver; $\mathbf{4}$, testis; $\mathbf{5}$, skeletal muscle; $\mathbf{6}$, hog brain microtubule proteins. Arrowheads indicate start of running gels. Brackets, position of $200000-240000$ mol. wt. polypeptides. Tub, tubulin.

cell lines. It was relatively high in the cases of $\mathrm{C} 6, \mathrm{CHO}, 3 \mathrm{~T} 6$, HeLa (Figure 1A, lanes 2-5) and $\mathrm{PtK}_{2}$ (not shown) cells, where it came close to that of neuroblastoma $\mathrm{N}_{2} \mathrm{~A}$ cells (Figure 1A, lane 1), a neuronal cell type tested for comparison. In other cases (SV 3T3, human fibroblasts, MDBK) high mol. wt. proteins, particularly MAP-1, were barely detectable. Besides tubulin the major components present in these microtubule-enriched fractions in most cases were proteins of mol. wt. $\sim 40000$, presumably actin, and polypeptides in the mol. wt. range of $200000-240000$ (Figure 1A, bracket). Polypeptides co-migrating with brain MAP-1 and MAP-2 in microtubule-enriched fractions from rat tissues were clearly visible only in overloaded gels, after staining with Coomassie Blue (Figure 1B). The major components of taxolpolymerized tissue fractions were unidentified polypeptides of various mol. wts. As in the case of cultured cells, a group of proteins of mol. wt. between 200000 and 240000 (Figure 1B, bracket) and proteins, probably including actin, of mol. wt. lower than that of tubulin were also prominent. Tubulin itself was rarely a major component except in taxol-precipitates from pituitary gland (Figure 1B, lane 1). Note that the sample of pituitary gland was highly enriched in high mol. wt. MAPs and resembled, in its protein composition, repeatedly cycled microtubule proteins from mammalian brain (Figure 1B, lane 6).

Figure 2 shows immunoblottings of taxol-precipitates from various sources using antisera raised individually to MAP-1 and MAP-2 (Wiche et al., 1983a). With the antiserum to MAP-1 a positive reaction of polypeptides co-migrating with MAP-1 was observed for four of the five cultured cell lines examined, namely $\mathrm{C} 6$ (data not shown), $\mathrm{CHO}, 3 \mathrm{~T} 6$ and $\mathrm{N}_{2} \mathrm{~A}$ cells (Figure $2 \mathrm{~A}$, lanes $1-3$ ). With $3 \mathrm{~T} 6$ cells an additional cross-reactive band was observed at mol. wt. $\sim 180000-190000$. Polypeptides migrating at the position of MAP-2 were not immunoreactive with this antiserum, except for $\mathrm{N}_{2} \mathrm{~A}$ cells, the only cell line of neuronal origin tested. No cross-reactive protein components were observed with samples from HeLa cells (data not shown). With respect to non-neuronal tissues, cross-reactive bands at the position of MAP-1 were observed in the case of pituitary, heart and testis

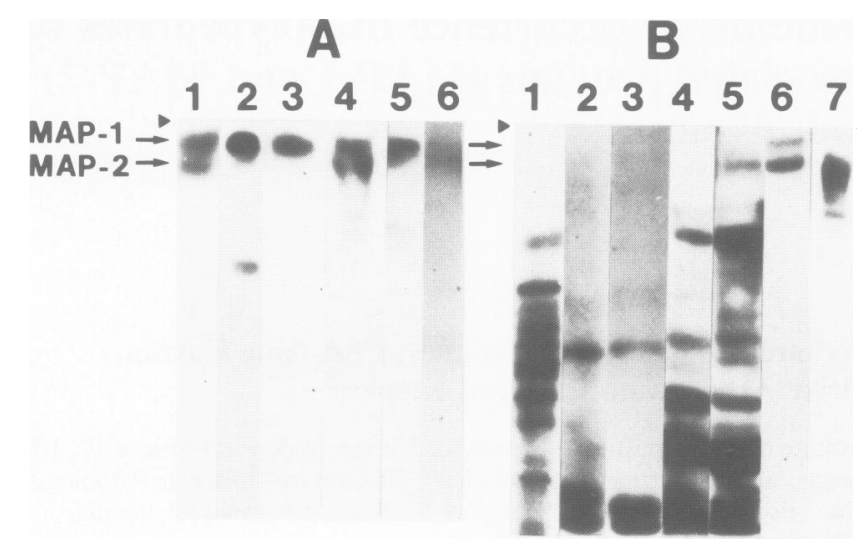

Fig. 2. Immunoblotting using antibodies to MAP-1 (A) and MAP-2 (B). Taxol-precipitates similar to those shown in Figure 1 were subjected to immunoblotting as described in the text. A, lanes: $1, \mathrm{~N}_{2} \mathrm{~A}$ cells; 2, 3T6 cells; 3, CHO cells; 4 , pituitary gland; 5 , heart; 6 , testis. B, lanes: 1 , CHO cells; 2 and 3 , Swiss 3 T3 cells; 4 , heart; 5 , skeletal muscle; $6, \mathrm{~N}_{2} \mathrm{~A}$ cells;

7, pituitary gland. Whole serum was used in all lanes, except $\mathbf{B}$, lane $\mathbf{3}$, where affinity-purified antibodies to MAP-2 were applied. Arrowheads indicate start of running gels.

(Figure 2A, lanes 4-6). With pituitary, whose origin is in part neuronal, and testis, an additional reaction was observed with components co-migrating with MAP-2. No crossreaction of polypeptides present in preparations from liver or skeletal muscle was detected (data not shown).

When similar taxol-precipitates from non-neuronal cells (CHO, Swiss 3T3, 3T6) and tissues (heart, skeletal muscle, testis) were analyzed using antiserum to MAP-2, multiple protein components predominantly of mol. wt. lower than that of MAP-2 were found to be immunoreactive (Figure 2B, lanes 1, 2, 4 and 5; and data not shown). In contrast, in similar preparations from cells and tissues of neuronal origin, such as $\mathrm{N}_{2} \mathrm{~A}$ cells and pituitary gland (Figure 2B, lanes 6 and 7 , respectively), polypeptides of the size of MAP-2 were the major cross-reactive species. [It should be noted, that when microtubule-enriched taxol-fractions were prepared from extracts of $\mathrm{N}_{2} \mathrm{~A}$ cells in non-isotonic conditions, polypeptides immunologically related to MAP-2 were not identified (Wiche et al., 1983a).] Preparations from liver showed no cross-reactivity at all (data not shown). The analysis of various cell fractions using affinity-purified antibodies to MAP-2 yielded gel profiles that were virtually identical to those obtained with whole serum (Figure 2B, lane 3; and unpublished data).

\section{Immunolocalization}

To reveal the location of antigens related to MAP- 1 and -2 in non-neuronal cultured cells, a total of 14 different cell lines (CHO, C6, 3T6, Swiss and BALB/c 3T3, HeLa, PtK 2 , MDBK, HSF, NADO, MDC, KRA, DOPA, MK) were studied by immunofluorescence microscopy using affinitypurified antibodies. In most of them, but especially in $\mathrm{CHO}$ (Figure 3A), 3T6, C6 (not shown) and human fibroblast cells (Figure 3C), antibodies to MAP-1 brightly stained networks of cytoplasmic filaments. These filaments were identified as microtubules by their sensitivity to colcemid (data not shown) and by double immunofluorescence microscopy using monoclonal antibodies to tubulin (Figure 3B and D). In general, the staining of microtubules with antibodies to MAP-1 was less intensive than that with antibodies to tubulin. This was particularly evident on microtubules located close to the cell 

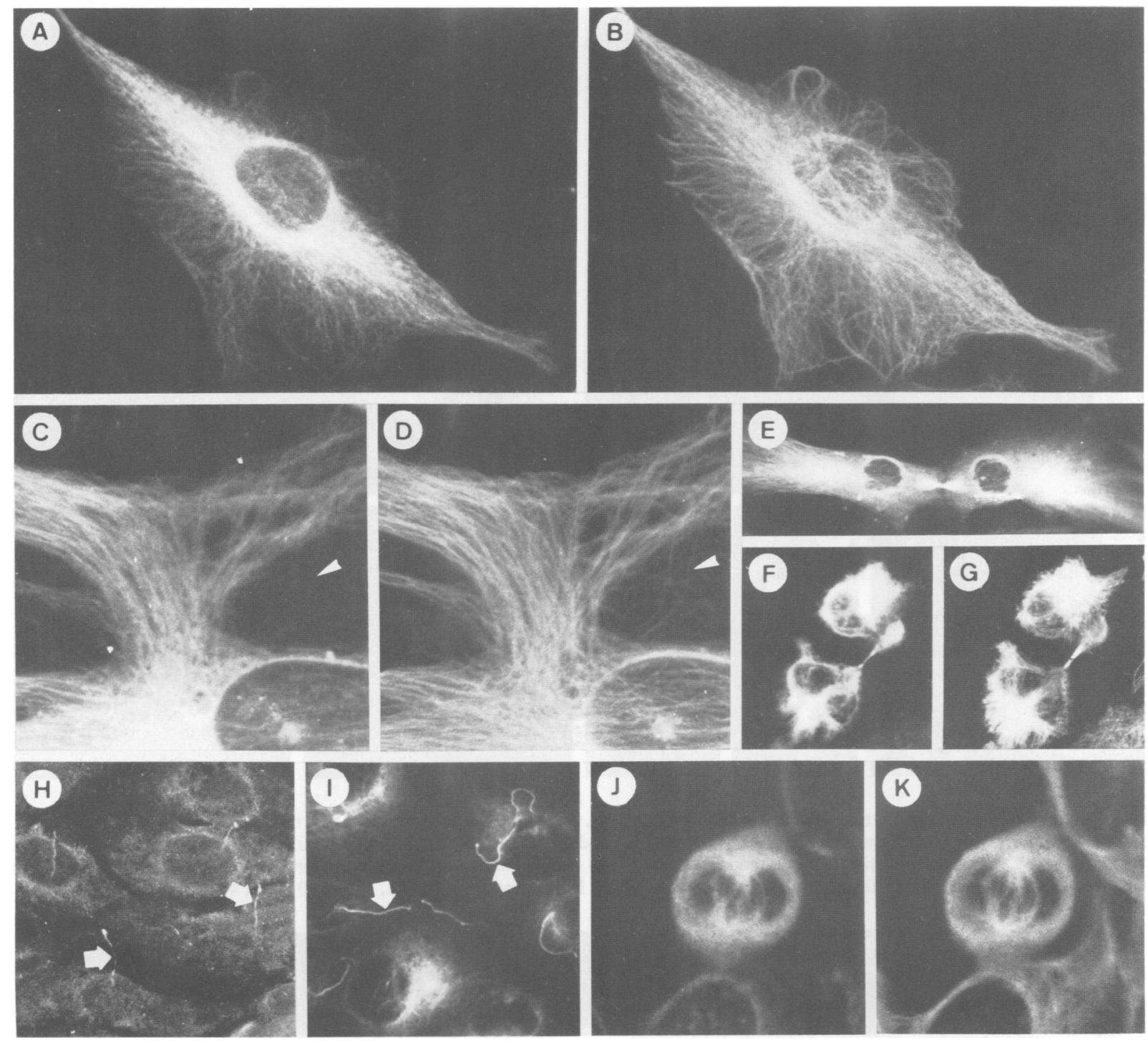

Fig. 3. Immunolocalization of MAP-1 in cultured cells. Double immunofluorescence microscopy of CHO (A, B, F, G), HSF (C, D) and BALB/c-3T3 (J, K) cells, and single immunofluorescence microscopy of MDC (E) and MDBK (H, I) cells are shown. A, C, E, F, and J, affinity-purified antibodies to MAP-1, fluorescein optics; B, D, G and $\mathbf{K}$, monoclonal antibodies to $\alpha$ - and $\beta$-tubulin, Texas red optics. $\mathbf{H}$, antiserum to MAP-1, fluorescein optics; I, rabbit antibodies to microtubule proteins, fluorescein optics. Arrowheads in $\mathbf{C}$ and $\mathbf{D}$ mark microtubules close to the cell periphery. Arrows in $\mathbf{H}$ and $\mathbf{I}$ indicate primary cilia. Magnifications: x 720 (A, B); x 660 (C, D); x 400 (E); x 450 (F, G); x 500 (H, I); x 960 (J, K ).

periphery (Figure 3C and D; arrowheads). Furthermore, in some cases, e.g., mouse $3 \mathrm{~T} 3$ cells, only a small fraction of the cells clearly displayed MAP-1-decorated filaments. Instead, often diffuse staining of the cytoplasm was observed. In $\mathrm{HeLa}, \mathrm{PtK}_{2}$ and MDBK cells hardly any stained filaments were seen. In addition to cytoplasmic microtubules, in a variety of cell lines antibodies to MAP-1 stained midbodies of telophase cells (Figure 3E and F), mitotic spindles (Figure 3J), and primary cilia (Figure $3 \mathrm{H}$ ). Except for primary cilia the staining of these structures with antibodies to MAP-1 was generally as bright as that with antibodies to tubulin (Figure $3 \mathrm{G}$ and $\mathrm{K})$.

Similar to MAP-1-antibodies, monospecific antibodies to MAP-2 decorated microtubules of the cytoplasm (Figure 4A and $C$ ), the spindle (Figure 4D and F), and midbodies (Figure $4 G)$. In general, the staining with antibodies to MAP-2 was less intensive than that with antibodies to MAP-1, probably because antigens related to MAP-2 were less abundant than MAP-1 antigens. As with MAP-1 antibodies, in some cases, e.g., 3T3 cells, cytoplasmic microtubules were visible after MAP-2 staining only in a fraction of the whole cell population or hardly at all (HeLa, MDBK, $\mathrm{PtK}_{2}$ cells). Moreover, in contrast to tubulin-specific staining, in some cases the region around the spindle poles was more brightly stained than the spindle fibers (Figure 4D and E). In telophase cells, contractile rings (Figure 4G, arrow) were stained by antibodies to MAP-2. Specific anti-MAP-2 staining was observed also at the leading edge of motile cells, peripheral regions of spreading cells and cell/cell contact zones of primary rat kidney cells (data not shown).

Treatment of cultured fibroblast cells with $0.5 \%$ Triton $\mathrm{X}-100$ in microtubule stabilization buffer prior to fixation diminished both MAP-1- and MAP-2-specific staining (Figure 5B and D). This treatment evidently had no effect on the integrity of microtubules per se, as shown by the persisting anti-tubulin decoration (Figure 5E). Thus, the association of MAP-1- and MAP-2-related antigens with cytoplasmic microtubules appears to be detergent sensitive. Similar 

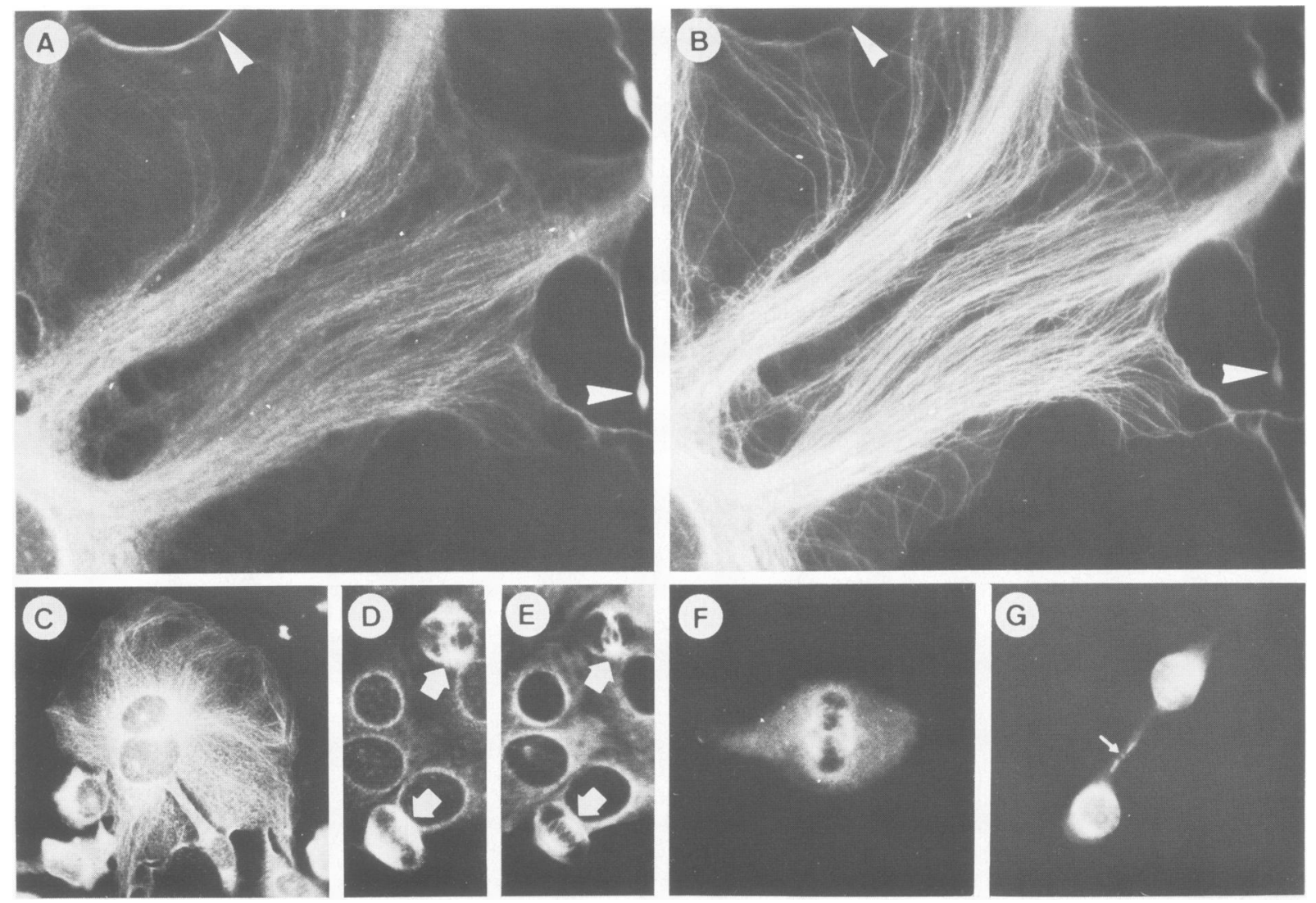

Fig. 4. Immunolocalization of polypeptides related to MAP-2 in cultured cells. Double immunofluorescence microscopy of HSF (A, B) and BALB/c 3T3 cells (D, E), and single immunofluorescence microscopy of CHO (C), MDC (F) and C6 (G) are shown. A, C, D, F and G, affinity-purified antibodies to MAP-2, fluorescein optics; B and E, monoclonal antibodies to $\alpha$ - and $\beta$-tubulin, Texas red optics. Note differential staining of peripheral structures in $\mathbf{A}$ and $\mathbf{B}$ (arrowheads); arrows mark mitotic cells in D and E and contractile ring in G. Magnification: x 640 (A, B); x 280 (C); x 490 (D, E, F, G).
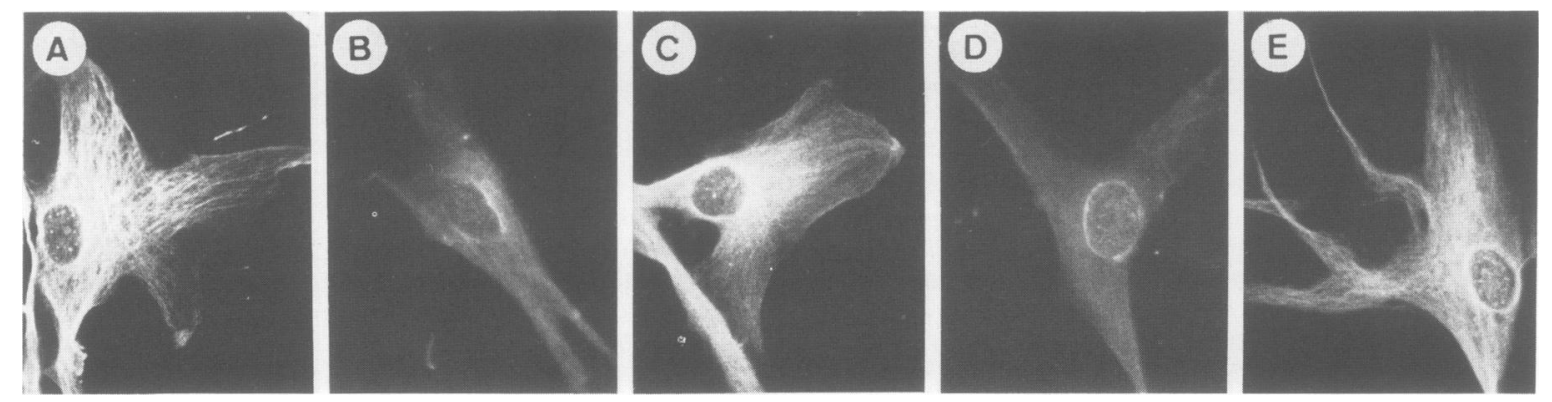

Fig. 5. Extraction of antigens related to MAP-1 and MAP-2 with $0.5 \%$ Triton X-100. Immunofluorescence microscopy of HSF cells using affinity-purified antibodies to MAP-1 (A, B), MAP-2 (C, D) or monoclonal antibodies to tubulin (E) is shown. A and C, untreated controls; B, D and E, extracted cells (see text). Photographic exposure and processing times were the same for all pictures. Note diminished staining in B and D compared with $\mathbf{A}$ and $\mathbf{C}$. Magnifications: approximately $\mathrm{x} 300$.

observations were reported by Schliwa et al. (1981) with regard to an MAP of mol. wt. $\sim 200000$.

Figure 6 shows the localization of MAP-1- and MAP-2antigens on frozen sections of various non-neuronal tissues from rat, as revealed by immunofluorescence microscopy using affinity-purified antibodies. Among the tissues containing typical microtubule structures, cilia of the pseudostratified tracheal columnar epithelium were stained with antibodies to both MAPs (Figure 6B and $\mathrm{C}$ ), although considerably less brightly than with antibodies to tubulin (Figure 6A). Immunoreactivity of MAP antibodies was also observed with epithelial cells and some connective tissue material. On sections of testis, we observed bright staining of tail and head regions of spermatozoa, with both MAP-1- and MAP-2antibodies (Figure 6D and E, respectively). In addition, Sertoli cells and late spermatids adhering to Sertoli cells were strongly immunoreactive. In kidney, cells in the glomeruli, most likely representing mesangial cells, were brightly stained using antibodies to MAP-1 (Figure 6F) as well as antibodies to MAP-2 (Figure 6G), while podocytes, characterized by their feet processes, and endothelial cells, were not reactive. Here, both MAP-antigens showed clear co-distribution with tubulin (Figure 6L and $\mathrm{M}$ ) as revealed by double immunofluorescence microscopy. In skeletal (Figure $6 \mathrm{H}$ and I) as well as cardiac (Figure $6 \mathrm{~J}$ and $\mathrm{K}$ ) muscle, striations, most likely Z-lines, were stained using both antibodies to MAPs. Inter- 

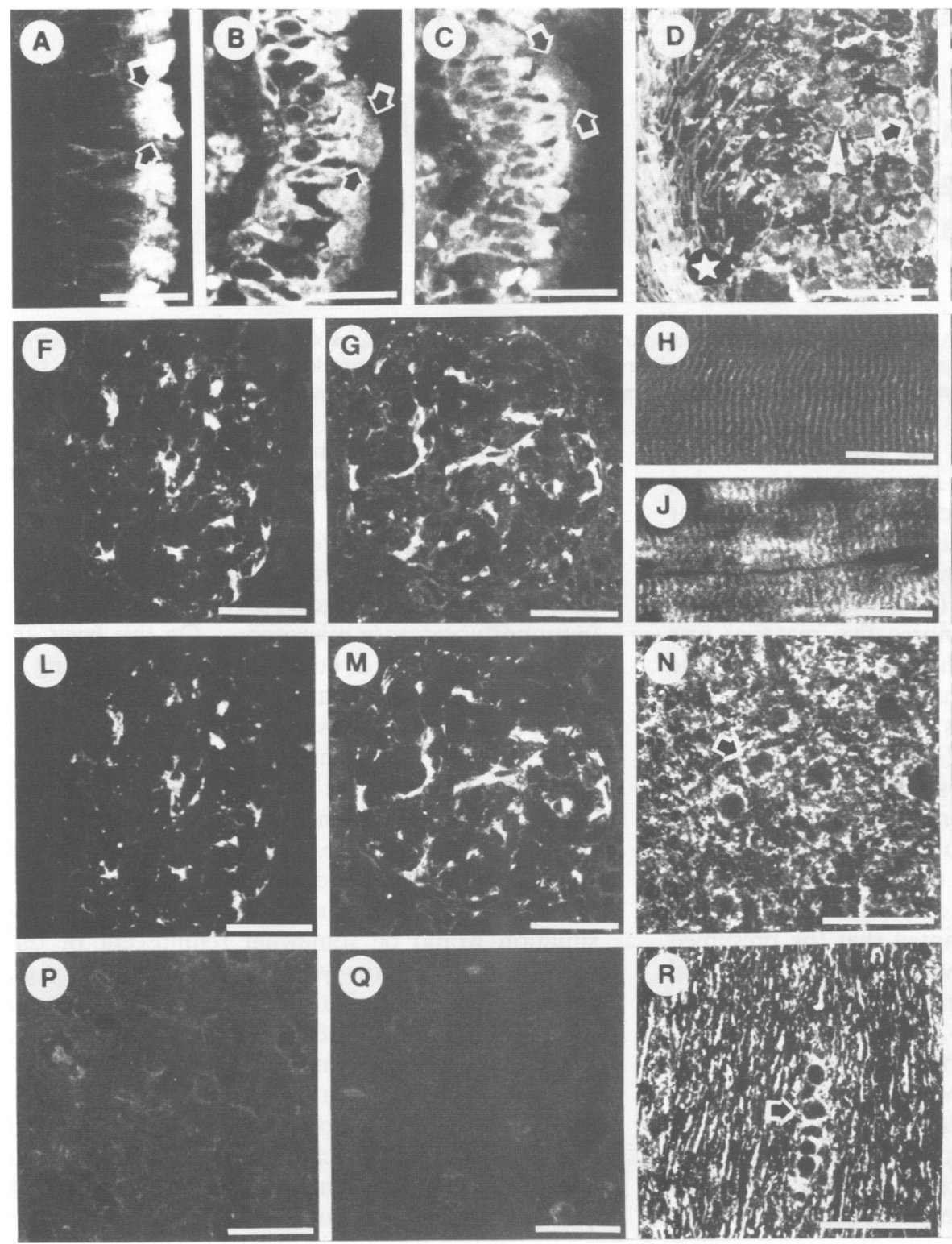
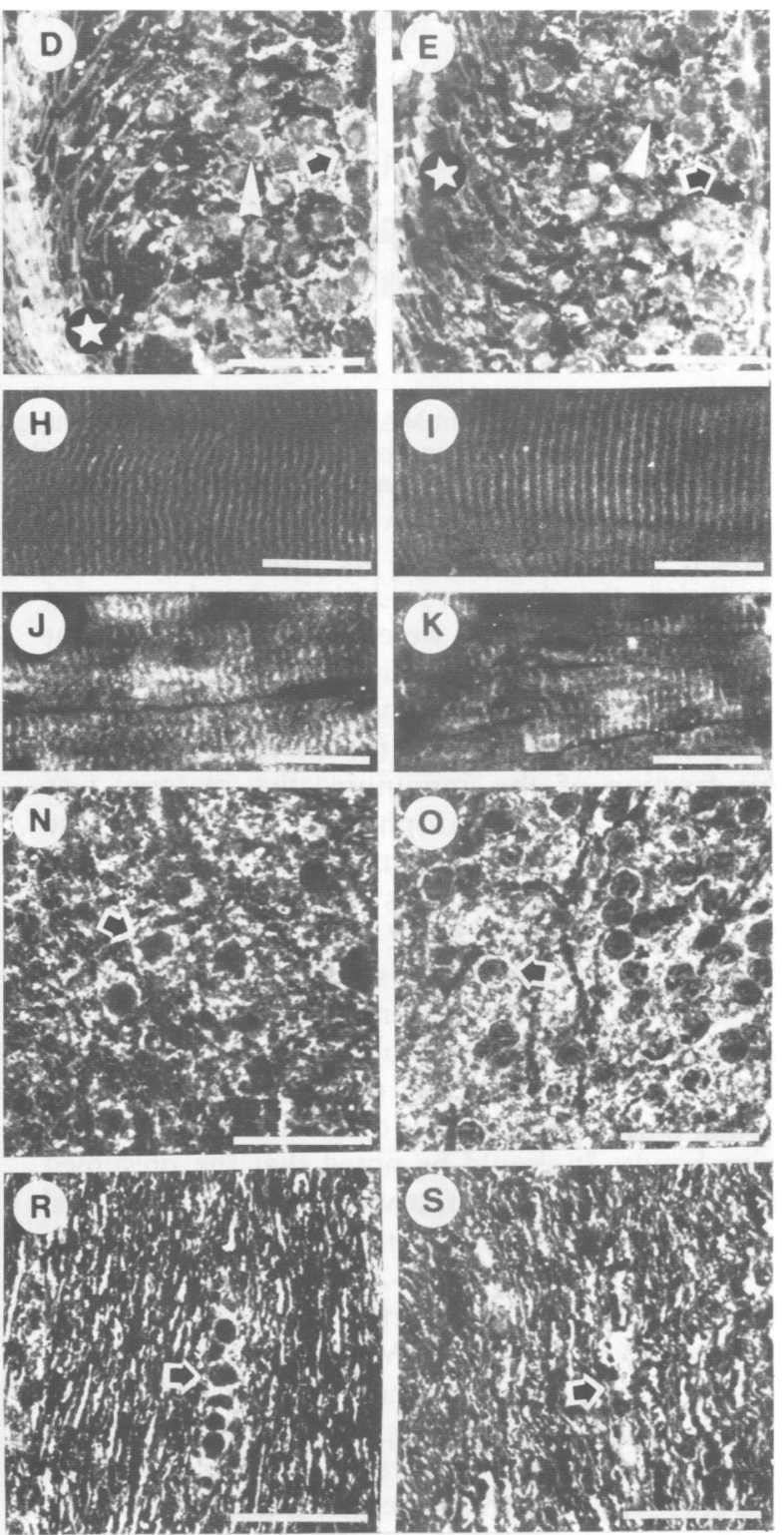

Fig. 6. Immunolocalization of polypeptides related to MAP-1 and MAP-2 on frozen sections of rat tissues. A, B and C, trachea; D and E, testis; F, G, L and $\mathbf{M}$, kidney; $\mathbf{H}$ and $\mathbf{I}$, skeletal muscle; $\mathbf{J}$ and $\mathbf{K}$, cardiac muscle; $\mathbf{N}$ and $\mathbf{O}$, adenohypophysis; $\mathbf{P}$ and $\mathbf{Q}$, liver; $\mathbf{R}$ and $\mathbf{S}$, neurohypohysis. $\mathbf{A}, \mathbf{L}$ and $\mathbf{M}$, monoclonal antibodies to tubulin. B, D, F, H, J, N, P and $\mathbf{R}$, affinity-purified antibodies to MAP-1. C, E, G, I, K, O, Q and S, affinity-purified antibodies to MAP-2. Arrows in A, B, and $\mathbf{C}$ denote location of tracheal cilia. Asterisks and arrowheads in $\mathbf{D}$ and $\mathbf{E}$ mark spermatozoa and late spermatides, respectively. Arrows in $\mathbf{D}$ and $\mathbf{E}, \mathbf{N}$ and $\mathbf{O}, \mathbf{R}$ and $\mathbf{S}$ point at Sertoli cells of testis, endocrine cells of adenohypophysis and axons of secretory nerve cells of neurohypophysis, respectively. Bars: $20 \mu \mathrm{m}$ (A, B, C, H, I, J, K, P, Q); $40 \mu \mathrm{m}$ (D, E, F, G, L, M, N, O, R, S).

calated discs of cardiac muscle were negative. Striations were immunoreactive also in muscle of tongue (not shown). The examination of pituitary revealed strong staining of both the adenohypophysis (Figure $6 \mathrm{~N}$ and $\mathrm{O}$ ) and the neurohypophysis (Figure 6R and S). Endocrine cells in the adenohypophysis, unmyelinated axons of secretory nerve cells and the cytoplasm of pituicytes in the neurohypophysis were immunoreactive. The epithelium of Rathke's pouch and follicular cells forming the supporting stroma of the adenohypophysis were negative. On sections through liver neither of the MAP antibodies showed positive reactions (Figure 6P and Q). Using whole serum instead of affinity-purified antibodies, a very similar distribution of MAP antigens was found in tissues and cultured cells. Controls run with sera that were pre-absorbed with their respective immunogens were negative. Likewise, with rabbit-preimmune serum no positive reaction was observed with any of the tissue or cell lines tested (data not shown).

\section{Discussion}

Using affinity-purified rabbit antibodies, we demonstrate here for the first time in a comprehensive way the widespread occurrence of MAP-1- as well as MAP-2-related antigens in non-neuronal cells and tissues. With respect to the nature of polypeptides immunologically related to MAP-1, the interpretation of our data is straightforward, since in all cases tested the major cross-reactive components revealed on immunoblots were of the same mol. wt. as their neuronal counterparts. Thus, it seems justified to identify these proteins as MAP-1 from non-neuronal cells.

The situation regarding MAP-2-related polypeptides was 


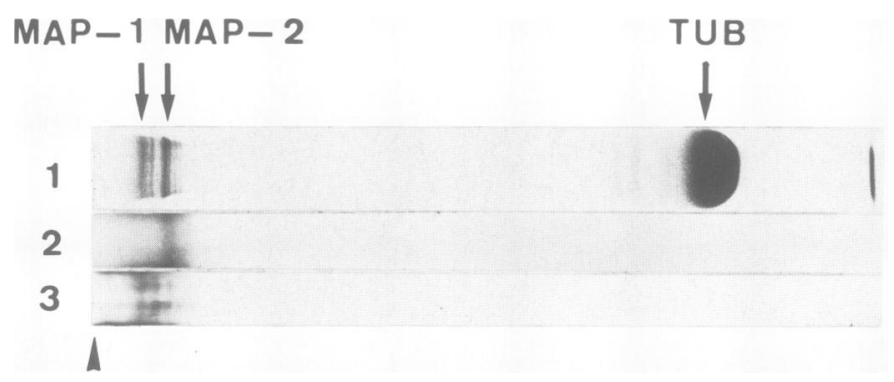

Fig. 7. Immunoprecipitation of hog brain MAP-1 and MAP-2 using affinity-purified antibodies. Microtubule proteins were iodinated and MAPs immunoprecipitated as described in the text. Immunoprecipitates were analyzed by electrophoresis on $7.5 \%$ polyacrylamide gels and autoradiography. 1, Coomassie Blue-stained hog brain microtubule protein standard. 2 and 3, autoradiographies using affinity-purified antibodies to MAP-1 and MAP-2, respectively.

more complex. For a total of six non-neuronal cell lines/tissues tested, the major cross-reactive bands revealed on immunoblots of taxol-pellets were of mol. wt. below that of brain MAP-2, while polypeptides co-migrating with MAP-2 were barely immunoreactive. Because of, (i) the multiplicity of cross-reactive bands, (ii) the fact that often a considerable fraction of the immunoreactive material was found at the front of the electrophoresis gel and, (iii) the demonstrated specificity of the immunoreaction, it is very likely that the immunoreactive bands were proteolytic breakdown products derived from MAP-2. An alternative possibility, namely, that the various cross-reactive proteins were genuinely distinct but shared common, highly conserved antigenic sites (situated, e.g., within tubulin-binding domains) cannot be ruled out. However, we consider this possibility unlikely among other things because of the multiplicity of immunoreactive bands. It should be noted that the presumed proteolytic activity might be effective only in non-neuronal cells, since in cells and tissues of neuronal origin polypeptides of mol. wt. lower than that of MAP-2 were barely detectable. In this context it is also noteworthy that neither $2 \mathrm{mM}$ phenylmethylsulphonyl fluoride (PMSF) nor $1 \mathrm{mM}$ EGTA had any effect on this activity. Finally, the observation of relatively large quantities of polypeptides co-migrating with MAP-2 in most taxol-pellets (Figure 1), but their apparent lack of cross-reactivity with antibodies to MAP-2 could be explained by the presence of heterogeneous protein species within the MAP-2 gel region. In a recent study with glioma C6 cells (Koszka et al., in preparation), a considerable part of the co-migrating material was identified as plectin (Wiche et al., 1982), a protein of mol. wt. 300000 that is immunologically unrelated to MAP-2.

When comparing immunoblots of taxol-precipitates from non-neuronal versus neuronal cells and tissues, an important difference was noticed. While with respect to most nonneuronal cells and tissues tested, the antiserum to MAP-1 recognized polypeptides that were distinct to those recognized by antiserum to MAP-2, in cells and tissues of neuronal origin (pituitary, $\mathrm{N}_{2} \mathrm{~A}$ cells) both antisera showed some crossreaction with MAP-1- and MAP-2-antigens (see, e.g., Figure 2A, lanes 1 and 4; and Figure 2B, lane 6). Since a similar situation had previously been encountered with mammalian brain MAPs (Wiche et al., 1983a; Herrmann et al., 1984) we conclude that the common antigenic sites shared by neuronal MAP-1 and MAP-2 in many cases are not shared among non-neuronal antigens. This, we believe, does not necessarily mean that most MAP-1- and MAP-2-related proteins from non-neuronal sources are completely devoid of common antigenic determinants. Such determinants might, however, dif- fer from those of neuronal proteins, and consequently would not be detected by antibodies raised against neuronal components.

The extent of crossreactivity of the MAP-antisera with polypeptides from the various non-neuronal cells and tissues tested was generally in good agreement with that observed by immunofluorescence microscopy. On this basis and because of the notions discussed above regarding structural similarities of MAP-1- and MAP-2-molecules (see also Herrmann et al., 1984), we suggest that high-mol. wt. MAPs are tissue specific. Furthermore, we suggest that polypeptides related to MAPs have partially similar primary structures which in turn are responsible for similar function(s). The differential distribution, e.g. in brain tissue, and any distinct function(s) might be determined, however, by structural features that are unique to certain MAPs. If correct, this situation would be somewhat reminiscent of that recently revealed for spectrin-type polypeptides (see, e.g., Glenney and Glenney, 1983). To test this hypothesis, more antibodies with well defined specificities towards high mol. wt. MAPs from various tissues and cell types, and detailed chemical analysis will be necessary.

The association of polypeptides related to both, MAP-1 and MAP-2, with such diverse microtubule structures as those of the cytoplasm, the spindle, the midbody and the primary cilium of cultured cells, as well as cilia of tracheal epithelial tissue and tails of spermatozoa, suggests that both proteins are ubiquitous components of non-neuronal microtubules. Thus they have to be distinguished from proteins that seem to specifically associate with certain subpopulations of non-neuronal microtubules, for instance those of the mitotic spindle (Izant et al., 1982; Zieve and Solomon, 1982; Izant et al., 1983). The occurrence of diverse MAPs and the observation that even MAP-1 and MAP-2 are differentially distributed in neurons of brain (Wiche et al., 1983a), support the view that the various functions of microtubules are regulated at least in part by distinct MAPs. The identification of polypeptides related to MAPs, in particular MAP-2, also at sites where microtubule structures are generally missing, as reported here, suggests that high mol. wt. MAPs can also fulfil function(s) that are independent of pre-formed microtubules. These might include the cross-bridging of microfilaments as suggested by in vitro studies (Satillaro et al., 1981; Griffith and Pollard, 1982) or the guiding of newly forming microtubules, as implied from studies on developing dendrites (Bernhardt and Matus, 1982). Being of widespread occurrence in neuronal as well as non-neuronal cells and tissues, it is likely that these polypeptides play important roles as structural as well as dynamic elements of the cytoskeleton. 
After submission of this manuscript, Bloom et al. (1984) reported on the distribution of MAP-1 in non-neuronal cultured cells using a monoclonal antibody to a MAP-1 subcomponent. Their results are in general agreement with our data on MAP-1 except that only punctuate staining of cytoplasmic microtubules was reported. The uniform and generally more intensive staining of microtubule structures demonstrated here probably reflects the higher abundance of antigenic sites recognized by polyclonal compared with monoclonal antibodies.

\section{Materials and methods}

\section{Cells and tissues}

Specifications regarding the origin of rat glioma C6, mouse BALB/c 3T3, mouse SV 101, Chinese hamster ovary (CHO-K1), rat kangaroo $\mathrm{PtK}_{2}$, and human HeLa S3 cells have been given previously (Wiche and Baker, 1982). In addition, we used mouse Swiss 3T3, mouse 3T6 and bovine MDBK cells obtained from the American Type Culture Collection, rat R-1 cells, provided by Dr. Friis, Giessen, a diploid primary human skin fibroblast cell line in low passage number (HSF), kindly provided by Dr. Vetterlein, Vienna, a series of primary human skin fibroblast cell lines (NADO, DOPA, MDC, KRA) generously provided by Dr. Schweiger, Innsbruck, and primary mouse kidney (MK) cells, provided by Dr. Wawra, Vienna. Cell cultures were routinely grown in plastic T-flasks, or stationary glass or roller bottles using Dulbecco's modified Eagle's medium supplemented with newborn or fetal calf serum.

For preparative purposes, cell cultures were extensively rinsed with $140 \mathrm{mM}$

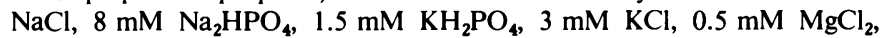
$0.9 \mathrm{mM} \mathrm{CaCl} 2.2 \mathrm{H}_{2} \mathrm{O}$ (buffer $\mathrm{A}$ ) prior to harvest using a rubber policeman. For immunofluorescence microscopy, cells were trypsinized and plated onto glass coverslips usually 12 or $24 \mathrm{~h}$ before fixation. For extraction with detergent, cells grown on coverslips were washed for $30 \mathrm{~s}$ at room temperature with microtubule stabilization buffer [0.1 M piperazine-1,4-bis-(2-ethanesulfonic acid) disodium salt, pH 6.9, $10 \mathrm{mM}$ EGTA, $2.5 \mathrm{mM}$ guanidine triphosphate, $4 \%$ polyethylene glycol 6000 ], incubated for $5 \mathrm{~min}$ in the same buffer containing $0.5 \%$ Triton X-100 at room temperature and washed twice with stabilization buffer prior to fixation in cold ethanol for $5 \mathrm{~min}$.

Tissues (liver, heart, tongue, skeletal muscle, testis, trachea, kidney and pituitary) were taken from the rat and homogenized for preparative purposes with minimal delay. For immunolocalization experiments, tissues were processed as described previously (Wiche et al., 1983b).

\section{Preparation of cell and tissue fractions}

For the preparation of cultured cell fractions enriched in microtubule proteins, the taxol-dependent polymerization procedure of Vallee (1982) with important modifications (Koszka et al., in preparation) was used. Cells harvested were centrifuged at $300 \mathrm{~g}$ for $5 \mathrm{~min}$ and the cell pellets resuspended in $1 \mathrm{ml} / 1 \mathrm{~g}$ (wet weight) of $100 \mathrm{mM} 2$-( $\mathrm{N}$-morpholino)ethanesulfonic acid, pH 7.0, $0.52 \mathrm{M}$ sucrose, $0.5 \mathrm{mM} \mathrm{MgCl}_{2}, 1 \mathrm{mM}$ EGTA, $1 \mathrm{mM}$ GTP, $2 \mathrm{mM}$ PMSF (assembly buffer). The cells were then gently broken with a Dounce homogenizer at $4^{\circ} \mathrm{C}$, and the homogenate centrifuged at $100000 \mathrm{~g}$ for $60 \mathrm{~min}$ at $4^{\circ} \mathrm{C}$. To the supernatants, taxol and GTP were added to final concentrations of $20 \mu \mathrm{M}$ and $2 \mathrm{mM}$, respectively, and incubations carried out for $30 \mathrm{~min}$ at $37^{\circ} \mathrm{C}$. Microtubules and any other protein aggregates formed were precipitated by centrifugation at $100000 \mathrm{~g}$ for $60 \mathrm{~min}$ at $37^{\circ} \mathrm{C}$; and finally resolved in electrophoresis sample buffer (Laemmli, 1970). For the preparation of fractions enriched in microtubule proteins from tissues, a similar protocol was followed except that, after having been minced with scissors, the tissues were homogenized with a motor driven glass teflon homogenizer.

\section{Preparation and characterization of affinity-purified antibodies}

The preparation of antisera to high mol. wt. MAPs, using as immunogens individual MAP-1 and MAP-2 components separated by preparative SDS-polyacrylamide gel electrophoresis, has been described in detail previously (Wiche et al., 1983a). Monospecific antibodies to MAP-1 and MAP-2 were obtained by affinity purification following the procedure of Krohne et al. (1982), slightly modified as follows: microtubule proteins prepared according to Karr et al. (1979) were subjected to electrophoresis on $5 \%$ polyacrylamide gels $(1.5 \mathrm{~cm}$ thick) and then electrophoretically transferred to nitrocellulose sheets in $50 \mathrm{mM}$ sodium borate, $\mathrm{pH} 8.9,2 \mathrm{mM}$ EDTA, $4 \mathrm{mM}$ 2-mercaptoethanol, $20 \%$ methanol for $24 \mathrm{~h}$. (The conditions of electrophoresis were such that after blotting MAP-1 and MAP-2 bands were sufficiently separated to unambiguously permit their individual isolation.) Small nitrocellulose strips containing exclusively MAP-1 or MAP-2 bands were incubated with $200 \mu \mathrm{l}$ of antisera diluted 1:50 in buffer $A$ and $0.1 \%$ bovine serum albumin (BSA). The end volume of the solution containing the eluted antibodies after dialysis and concentration was 100-150 $\mu \mathrm{l}$. Nitrocellulose strips were stored in buffer $\mathbf{A}$ containing $0.02 \% \mathrm{NaN}_{3}$ at $4^{\circ} \mathrm{C}$.

The specificity of affinity-purified antibodies was assayed by immunoprecipitation following the protocol given by Herrmann et al. (1984) except for (i) microtubule proteins iodinated by Iodogen (Herrmann et al., 1984) were used, (ii) immunocomplexes were precipitated by IgG sorb (The Enzyme Center, Boston) and (iii) no pre-incubation of the antigens with the immunosorbent was performed. The electrophoretic analysis of immunoprecipitates is shown in Figure 7. A comparison with published data (Herrmann et al., 1984; Figure 6) reveals similar specificities of affinity-purified antibodies and whole sera.

\section{Gel electrophoresis and immunoblotting}

Electrophoresis in the presence of SDS was performed according to the method of Laemmli (1970) using $6.25 \%$ or $7.5 \%$ polyacrylamide gels. For immunoblotting, slab gels containing separated proteins were soaked in $4 \mathrm{M}$ urea, $50 \mathrm{mM}$ sodium borate, $2 \mathrm{mM}$ EDTA, $4 \mathrm{mM}$ 2-mercaptoethanol, $20 \%$ $(\mathrm{v} / \mathrm{v})$ methanol (buffer B) for $1 \mathrm{~h}$ and then the proteins were electrophoretically transferred to nitrocellulose sheets using buffer B without urea. Sheets were incubated with $140 \mathrm{mM} \mathrm{NaCl}, 8 \mathrm{mM} \mathrm{Na} \mathrm{HPO}_{4}, 1.5 \mathrm{mM} \mathrm{KH} \mathrm{KO}_{4}$, $3 \mathrm{mM} \mathrm{KCl}$ (buffer $\mathrm{C}$ ) containing $3 \% \mathrm{BSA}$ at $37^{\circ} \mathrm{C}$ for $45 \mathrm{~min}$. Then they were overlaid with antisera diluted 1:50 in buffer $C$ supplemented with $3 \%$ $\mathrm{BSA}$, and kept at $37^{\circ} \mathrm{C}$ in a moist atmosphere for $2 \mathrm{~h}$. The sheets were washed extensively with buffer $C$ and subsequently overlaid $(90 \mathrm{~min}$ ) with $0.5 \mathrm{mg}$ (4.6 $x 10^{8}$ c.p.m.) ${ }^{125} \mathrm{I}$ ]protein $\mathrm{A} / \mathrm{ml}$ of buffer $\mathrm{C}$. Sheets were again extensively rinsed with water, air dried, and finally exposed to X-ray film.

\section{Immunofluorescence microscopy}

Cultured cells adhering to coverslips were permeabilized by immersion in methanol for $5 \mathrm{~min}$ at $-20^{\circ} \mathrm{C}$, air dried and then processed for immunofluorescence microscopy as described previously (Wiche and Baker, 1982). Frozen tissue sections were prepared and processed as described in detail by Wiche et al. (1983b). On cultured cells as well as on tissue sections, primary antibodies were used either undiluted (affinity purified antibodies to MAP-1 and MAP-2), or at dilutions (in buffer C) of 1:500 [monoclonal antibodies to $\alpha$ - and $\beta$-tubulin (The Radiochemical Center, Amersham)], or 1:20 (rabbit antiserum to porcine microtubule proteins [Wiche and Baker, 1982]) or 1:40 (rabbit antiserum to MAP-1). For cultured cells the following secondary antisera were used: fluorescein-conjugated goat anti-rabbit IgG (Nordic I aboratories, Lausanne) diluted 1:20 in buffer $\mathrm{C}$, rhodamine-conjugated goat antirabbit IgG (Nordic Laboratories, Lausanne) diluted 1:50 in buffer C, Texas red-conjugated donkey anti-rabbit IgG (The Radiochemical Center, Amersham) diluted 1:30 in buffer $C$, and Texas red-conjugated sheep anti-mouse IgG (The Radiochemical Center, Amersham) diluted 1:30 in buffer C. On tissue sections fluorescein-conjugated swine anti-rabbit IgG (Dako-Immunoglobulins, Copenhagen) diluted 1:15 in buffer $\mathrm{C}$ and Texas red-conjugated sheep anti-mouse IgG diluted 1:30 in buffer $C$ were used. For double immunofluorescence microscopy specimens were incubated, in sequence, with antibodies to MAPs, corresponding secondary antibodies, antibodies to tubulin and corresponding secondary antibodies. Specimens were viewed in a Leitz-Orthoplan (cultured cells) or Reichert-Polyvar (tissues) fluorescence microscope using epi-illumination. Photographs were taken with Ilford HP5 or Kodak Tri-X Pan film.

\section{Acknowledgements}

We thank Professor P. Heistracher for the use of his photolaboratory and Dr. Herrmann and the reviewers for helpful suggestions regarding the manuscript. This research was supported by grants 4571 and 5263 (to G.W.) of the Österreichischer Fonds zur Förderung der Wissenschaftlichen Forschung (Austrian Science Research Fund) and grants from the HochschulJubiläumsstiftung der Stadt Wien (to R.K. and G.W.).

\section{References}

Amos,L.A. (1977) J. Cell Biol., 72, 642-654.

Bernhardt,R. and Matus,A. (1982) J. Cell Biol, 92, 589-593.

Bloom,G.S., Luca,F.C. and Vallee,R.B. (1984) J. Cell Biol., 98, 331-340.

Bulinsky,J.C. and Borisy,G.G. (1979) Proc. Natl. Acad. Sci. USA, 76, 293297.

Cleveland,D.W., Spiegelman,B.M. and Kirschner,M.W. (1979) J. Biol. Chem., 254, 12670-12678.

Conolly,J.A. Kalnins, V.I., Cleveland,D.W. and Kirschner,M.W. (1978) J. Cell Biol., 76, 781-786.

Dentler,W.L., Granett,S. and Rosenbaum,J.L. (1975) J. Cell Biol., 65, $237-$ 241.

Doenges,K.H., Nagle,B.W., Uhlmann,A. and Bryan,J. (1977) Biochemistry (Wash.), 16, 3455-3459.

Glenney,J.R.,Jr. and Glenney,P. (1983) Cell, 34, 503-512. 
Greene,L.A., Liem,R.K.H. and Shelanski,M.L. (1983) J. Cell Biol., 96, 7683.

Griffith,L.M. and Pollard,T.D. (1982) J. Biol. Chem., 257, 9143-9151.

Herrmann,H., Pytela,R., Dalton,J.M. and Wiche,G. (1984) J. Biol. Chem., 259, 612-617.

Herzog,W. and Weber,K. (1978) Eur. J. Biochem., 92, 1-8.

Izant,J.G. and McIntosh,J.R. (1980) Proc. Natl. Acad. Sci. USA, 77, 47414745 .

Izant,J.G., Weatherbee,J.A. and McIntosh,J.R. (1982) Nature, 295, 248-250.

Izant,J.G., Weatherbee,J.A. and McIntosh,J.R. (1983) J. Cell Biol., 96, 424 434.

Karr,T.L., White,H.D. and Purich,D.L. (1979) J. Biol. Chem., 254, 61076111.

Klein,I., Willingham,M. and Pastan,I. (1978) Exp. Cell Res., 114, 229-238.

Krohne,G., Stick,R., Kleinschmidt,J.A., Moll,R., Franke,W.W. and Hausen,P. (1982) J. Cell Biol., 94, 749-754.

Kuznetsov,S.A., Rodionov,V.I., Bershadsky,A.D., Gelfand,V.I. and Rosenblat,V.A. (1980) Cell Biol. Int. Rep., 4, 1017-1024.

Kuznetsov,S.A., Rodionov,V.I., Gelfand,V.I. and Rosenblat,V.A. (1981) FEBS Lett., 135, 241-244.

Laemmli,U.K. (1970) Nature, 227, 680-685.

Murphy,D.B. and Borisy,G.G. (1975) Proc. Natl. Acad. Sci. USA, 72, 26962700.

Nagle,B.W., Doenges,K.H. and Bryan,J. (1977) Cell, 12, 573-586.

Peloquin,J.G. and Borisy,G.G. (1979) J. Cell Biol., 83, 338a (abstract).

Satillaro,R.F., Dentler,W.L. and LeCluyse,L.E. (1981) J. Cell Biol., 90, $467-$ 473.

Schliwa,M., Euteneuer,V., Bulinski,J.C. and Izant,J.G. (1981) Proc. Natl. Acad. Sci. USA, 78, 1037-1041.

Sherline,P. and Schiavone,K. (1977) Science (Wash.), 198, 1038-1044.

Sheterline,P. (1978) Exp. Cell Res., 115, 460-464.

Sloboda,R.D., Dentler,W.L. and Rosenbaum,J.L. (1976) Biochemistry (Wash.), 15, 4497-4505.

Sloboda,R.D. and Dickersin,K. (1980) J. Cell Biol., 87, 170-179.

Valdivia,M.M., Avila,J., Coll,J., Colaco,C. and Sandoval,I.V. (1982) Biochem. Biophys. Res. Commun., 105, 1241-1249.

Vallee,R.B. (1982) J. Cell Biol., 92, 435-442.

Vallee,R.B. and Davis,S.E. (1983) Proc. Natl. Acad. Sci. USA, 80, 13421346.

Weatherbee,J.A., Luftig,R.B. and Weihing,R.R. (1978) J. Cell Biol., 78, 4757.

Weatherbee,J.A., Sherline,P., Mascardo,R.N., Izant,J.G., Luftig,R.B. and Weihing,R.R. (1982) J. Cell Biol., 92, 155-163.

Wiche,G. and Cole,R.D. (1976) Proc. Natl. Acad. Sci. USA, 73, 1227-1231.

Wiche,G. and Baker,M. (1982) Exp. Cell Res., 138, 15-29.

Wiche,G., Herrmann,H., Leichtfried,F. and Pytela,R. (1982) Cold Spring Harbor Symp. Quant. Biol., 46, 475-482.

Wiche,G., Briones,E., Hirt,H., Krepler,R., Artlieb,U. and Denk,H. (1983a) EMBO J., 2, 1915-1920.

Wiche,G., Krepler,R., Artlieb,U., Pytela,R. and Denk,H. (1983b) J. Cell Biol., 97, 887-901.

Zieve,G. and Solomon,F. (1982) Cell, 28, 233-242.

Received on 17 January 1984; revised on 21 February 1984 